\title{
Preexisting left bundle branch block as a risk factor for left ventricular systolic impairment during pregnancy - case report
}

\section{Silvana Jovanova* \\ University Clinic of Cardiology, Skopje, Macedonia}

\author{
KEYWORDS: left bundle branch block, pregnancy, heart failure \\ CITATION: Cardiol Croat. 2014:9(9-10):438
}

*ADDRESS FOR CORRESPONDENCE: University Clinic of Cardiology, Vodnjanska 17, 1000 Skopje, Macedonia. Phone: +389-72231116 / E-mail: silvana_jovanova@yahoo.com

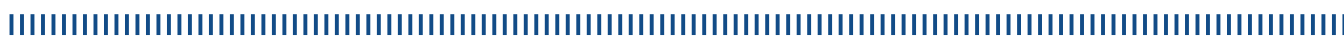

A 36 year old woman with preexisting left bundle branch block (LBBB) and decision for second pregnancy has been presented. There were no structural and functional heart abnormalities with left ventricular ejection fraction (LVEF) $>55 \%$ and preserved coronary reserve. She was symptomless till 32nd gestational week. Then, she began to feel malaise, with shortness of breath. Echocardiography revealed mild left ventricular (LV) dilation with decrease of LV ejection function to $45 \%$. Elective caesarean section was indicated in 36th gestational week because of heart failure symptoms and deterioration of LV systolic function. After the delivery the patient had clinical and echocardiographic improvement

Our case report reveals that LBBB in a pregnant woman should be taken seriously and may be associated with development of cardiomyopathy with overt heart failure during pregnancy, so pre-pregnancy counseling is highly advised in these patients.
RECEIVED:

September 21, 2014

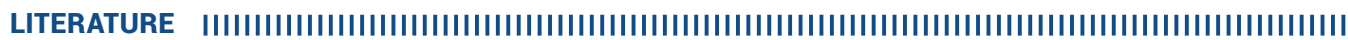

1. Zannad F, Huvelle E, Dickstein K, et al. Left bundle branch block as a risk factor for progression to heart failure. Eur J Heart Fail. 2007;9(1):7-14.

2. European Society of Gynecology (ESG); Association for European Paediatric Cardiology (AEPC); German Society for Gender Medicine (DGesGM), Regitz-Zagrosek V, Blomstrom Lundqvist C, Borghi C, et al; ESC Committee for Practice Guidelines. ESC Guidelines on the management of cardiovascular diseases during pregnancy: the Task Force on the Management of Cardiovascular Diseases during Pregnancy of the European Society of Cardiology (ESC). Eur Heart J. 2011;32:3147-97. 